\title{
Judicialização de todos os conflitos, pra quê? A jurisdição da arbitragem
}

\author{
Judicialization of all disputes, what for? Jurisdiction of arbitration
}

\author{
Ana Cristina Baruffi ${ }^{1}$
}

\begin{abstract}
Resumo
0 presente trabalho tem por objetivo demonstrar que a arbitragem é, ao lado do Poder Judiciário, meio capaz de entregar a prestação jurisdicional e, na mesma intensidade, buscando a dissolução da lide, relevando a importância da (continuidade da) relação entre as parte, embora ausente o Poder Judiciário, mas por ele autorizado (art. 114, $\S \S 10$ e 2o, da Constituição Federal), através de um procedimento que atende os princípios constitucionais do processo, cuja decisão terá apreciado o fato e o direito e, após o prazo nonagesimal, pode se tornar imutável pela coisa julgada material, tornando-se soberana, motivo pelo qual se pode dizer que a arbitragem é jurisdição propriamente dita.
\end{abstract}

Palavras Chave: Jurisdição; Procedimento; Arbitragem.

\section{Abstract}

This paper has as its purpose to show that arbitration is, besides the Judiciary, capable of giving rendering of jurisdiction and, in the same intensity, searching the end of the dispute, bringing into prominence the importance of (and permanence of) the relation between the litigations, even though absentee of the Judiciary but by him authorized (set forth by Federal Constitution Law, article 114, $\S \S 1^{\circ}$ e $2^{\circ}$ ), among a proceeding that attend the constitutional principles of process, from whose decision will appreciate the fact and the law and, after the ninetieth term, will became unchangeable by the material unappealable decision, becoming sovereigness, for this reason is possible to say that arbitration is exactly jurisdiction.

Keywords: Jurisdiction; Proceeding; Arbitration.

\section{Introdução}

\footnotetext{
${ }^{1}$ Bacharela em Direito pela Universidade Federal da Grande Dourados - UFGD. Advogada. Especialista em Metodologia do Ensino Superior pelo Centro Universitário da Grande Dourados - UNIGRAN. Mestranda em Direito Processual Civil, subárea Processo e Cidadania, Linha de Pesquisa Relações Negociais pela Universidade Paranaense - UNIPAR. Bolsista da CAPES.
} 
Vive-se, hoje, uma verdadeira revolução no âmbito do ordenamento jurídico. Exsurgem inúmeras discussões acerca do Poder Judiciário e de supostas reformas necessárias à agilidade do processo, estas baseadas nas mais diversas opiniões, variáveis, inclusive, de conteúdo segundo o setor de que promanam. ${ }^{2}$

As proposições voltadas a construção de um novo direito voltado a combater 0 desrespeito a dignidade humana, seja por ação ou omissão do Estado, acabam por se assemelhar àquelas propostas por Thomas M orus $^{3}$ “[...] e cria um país, embora imaginário, onde um governo, organizado da melhor maneira, proporciona ótimas condições de vida a um povo equilibrado e feliz, por nele vigorarem normas e/ou instituições políticas altamente aperfeiçoadas" (DELGADO, 2001, p. 8).

A celeuma centra-se sobre a busca do melhor procedimento, como funcionaria, tipos de recursos, dentre outros detalhes, capaz de responder de forma satisfatória aos anseios da sociedade no tocante à solução de seus conflitos de interesse pelo, ressalta-se, sempre, Poder Judiciário. E o instrumento para tanto, é e sempre será o processo, cujo objetivo único de sua existência é resolver conflitos.

Entretanto, é necessária uma virada metodológica, uma espada de Dâmaco capaz de por fim ao circulo vicioso de remendar, com pano novo, roupa velha, e pior, que não mais serve. Os remendos tornam-se destaques novos em procedimentos que, a cada dia, anacrônicos, forçam novos remendos, sem, contudo, atender aos reclamos do cidadão. Uma questão que se coloca diz sobre os desejos da sociedade. 0 que é preferível: um sistema perfeito (nos moldes da utopia de Thomas Morus) ou um sistema adequado aos princípios constitucionais de 1988, mas que funcione? Em outras palavras, todo conflito deve ser levado a efeito pelo poder judiciário porque assim determina o ordenamento jurídico ou existem outros meios de exercício da jurisdição que não pelo Estado?

\footnotetext{
${ }^{2}$ José Sarney em ensaio Uma Justiça que não será cega, disse: "Velho parlamentar, nunca vi uma matéria tão esmiuçada, tão estudada e de tantos e diversos interesses composta. A reforma tem dois pontos principais: 0 controle externo e a súmula vinculante." e ainda menciona: "O objetivo é acelerar 0 andamento dos processos que correm na Justiça, milhões. Basta citar que um juizado do Rio de Janeiro tem dois milhões de processos a julgar".

${ }^{3}$ Escritor inglês (1480-1535)
}

ReVISTA de DiReito Púbuco, LondRINA, V. 6, N. 2, P. 103-119, AGO/SET. 2011. 
E para melhorar a funcionalidade do sistema, como exemplificou Wambier em sua exposição oral ministrada no curso de Mestrado em Processo Civil e Cidadania da Universidade Paranaense - UNIPAR, em 23/03/2010, faz-se necessário

Estimular a diversidade de procedimentos, para tornar mais adequado o processo. Tem muito a ver com o objeto, com aquilo que se busca. Não melhora ou torna 0 processo mais adequado, massificar o procedimento. Situações diferentes devem ter procedimentos diferentes. Porém, há uma tendência em massificar 0 procedimento, tornando-o tudo ordinário. Quanto mais adequado for 0 procedimento, é possível que torne o processo mais célere, desde que atendas as regras do direito material em jogo. Porém, sem discurso ideológico (época da ditadura p.e. - exemplo Dec. Lei 911). (grifo nosso)

E continua,

Enfoque macro da instrumentalidade do processo - quando se fala de adequação do processo ela também tem que estar ligada a realidade social, que o processo tem também uma dimensão social. Para isso é preciso um pouco de coragem para entender que há uma constante e crescente incorporação de novos usuários do processo. 0 processo é um dos frutos da civilização, então tem que ser pensado e estudado neste contexto. Como um objeto para o qual a sociedade olha para ele com desejo. Tem que estar ligado ao conceito de dignidade da pessoa humana. (grifo nosso)

É a partir do reconhecimento desses novos usuários que se faz necessária esta virada metodológica, verdadeira revolução copernicana, no sentido de que não se pode restringir a solução dos conflitos apenas ao processo conduzido pelo Judiciário. A realidade contextual do processo de 1973 não é (nem pode ser) o mesmo de hoje, 2010. A sociedade se modificou. Os valores mudaram. Entranto, a utopia proposta por Thomas Morus não aconteceu. Os conflitos não deixaram de existir e, ao contrário, avolumaram-se, porque a população, nos últimos 10 anos, duplicou, requerendo-se, assim, diferentes maneiras de solucioná-los.

Nessa senda, as formas alternativas de solução de conflitos, e dentre elas, a arbitragem, (re)surgem diante da complexidade das atividades do Estado-Juiz e da burocratização do Judiciário, como meio capaz de entregar a prestação jurisdicional na mesma intensidade que o Estado, embora ausente o Poder Judiciário, mas por ele autorizado (art. 114, $\S \S 10$ e $2 \stackrel{\circ}{ }$, CF), e que visa a "consolidar os anseios daqueles que estão 
insatisfeitos com a demora na entrega da prestação jurisdicional, não só porque contribui para aumentar o grau de discórdia com o seu semelhante, mas, também, pelo fato de lhe ser negado o direito constitucional de ver o seu direito reconhecido em tempo razoável de ser possível o seu gozo e a sua fruição" (DELGADO, 2001, p. 16).

O fundamento do estado de direito da República Federativa do Brasil reporta-se ao princípio da dignidade da pessoa humana, o que significa que a Constituição deverá ser interpretada sempre tendo este princípio como seu norte, sua base, seu porto seguro. Por isso se estabeleceu um "piso vital mínimo" ou um "mínimo existencial" que no entender de Rocha (2005, p. 445), acoplou-se ao sentido essencial do princípio jurídico-constitucional da dignidade da pessoa humana. Tal conceito foi elaborado "[...] para dar efetividade ao princípio da possibilidade digna, ou da dignidade da pessoa humana possível, a ser garantido pela sociedade e pelo Estado" (Ibidem,, p. 445).

E o mesmo se estende ao processo, pois se verifica no processo 0 instrumento de busca de realização de diversos preceitos constitucionais. É um instrumento de duas vias de mão única, a de se ter um processo mais constitucional e a de garantir um direito constitucional através do processo. Wambier e Wambier (2003, p. 66) em suas anotações sobre a efetividade do processo sustentam que "O direito ao processo, portanto, com 0 tônus da efetividade, pertence ao conjunto desses direitos, ditos fundamentais, que estão ligados ao conceito de dignidade humana, princípio sobre o qual está assentada a estrutura do Estado brasileiro (art. 1ํ, inc. III da Constituição Federal)".

Para os autores,

Trata-se, por assim dizer, de direito fundamental instrumental, pois, 0 reconhecimento de rico elenco de direitos fundamentais (individuais e coletivos) no plano constitucional, sem a simultânea previsão de instrumentos processuais aptos a proporcionar sua eficaz e efetiva realização, resultaria no próprio esvaziamento da idéia de direitos fundamentais. $(2003$, p. 67)

Ou como apresentou Delgado, "O Direito Processual Civil, na verdade, esqueceu-se de que ele é instrumento para servir ao cidadão na busca de se identificar com a paz. E apenas caminho e que necessita ser trilhado com segurança e rapidez" (2001, p. 15). Sobre 0 assunto destaca Comoglio (apud COSTA, 2010, p. 83) que o processo constitucional deve ter as seguintes garantias mínimas:

Revista de Direito Púbuco, LondRINA, V. 6, N. 2, P. 103-119, AGO/SET. 2011. 


\begin{abstract}
a) A relação de instrumentalidade necessária entre 0 direito material e o processo, como premissa indispensável de sua atuação; b) 0 acesso às cortes de justiça e os fatores de desigualdade socioeconômica, que o limitam irrazoavelmente; c) a independência, a autonomia e a imparcialidade do juiz; d) exercício em condições adequadas e paritária, dos direitos de ação e defesa em juízo; e) o direito das partes a um processo justo e equo; f) a adequação e a efetividade dos instrumentos de tutela jurisdicional (de forma qualificada, diante de órgãos de justiça constitucional, e de forma ordinária, diante de órgãos de justiça comuns) das garantias processuais fundamentais.
\end{abstract}

É com fundamento nesses princípios constitucionais acima destacados que se situa a pergunta feita por Scaciota (2008, p. 11) “Não ofende ao princípio da dignidade humana, uma ação ficar parada por quase 10 (dez) anos numa sala de um tribunal para apreciação de um recurso, quando não no mais das vezes protelatório?"

As críticas ao processo são uníssonas: moroso, dificultoso, generalizado e democrático. Destaca Wambier (2010), que inobstante ter havido "um crescimento qualitativo e quantitativo, o mais importante foi a tomada de conhecimento dos seus direitos, aonde os malafortunados se tornam reivindicantes. Dentre os direitos/garantias, a que mais se ressalta é a da proteção processual do direito, ligado ao acesso à justiça". Porém, o Poder Judiciário não se encontra habilitado para receber o grande número de demandas que são ajuizadas diariamente, sobre os mais diversos assuntos.

A preocupação não é nova. Quando da criação dos Juizados Especiais, isso a mais de quatorze anos, a exposição de motivos destacava que estes tinham como principal objetivo, diminuir a grande carga de processos na Justiça Comum. Entretanto, o que se observa hoje? Os Juizados Especiais também se encontram atolados de processos, alguns cujas soluções poderiam ser dadas por vias extrajudiciais, porém que são levados ao judiciário pela falsa ideia de que a justiça somente pode ser alcançada se ditada pelo Poder Judiciário, o Estado.

Não é novidade na sociedade a menção aos métodos alternativos de solução de conflitos como mediação, conciliação e arbitragem, seja em âmbito processual ou administrativo. Porém, apenas a conciliação tem uma presença mais efetiva diante de sua imposição, seja na justiça comum, seja na do trabalho.

A (des)credibilidade desses métodos está associada ao senso comum, diariamente divulgado pelos meios de comunicação, de que quem soluciona os conflitos é o Estado, 
materializado pelo juiz, e que as outras formas alternativas de resolução de conflitos, não merecem crédito porque conduzidas por terceiros, iguais, que muitas das vezes nenhuma conexão tem com o poder público.

\section{Jurisdição x Judicialização}

Dizer o direito. Jurisdictio. Jurisdição.

Inobstante a história da humanidade trazer exemplos paradigmáticos de solução de conflitos pela via extrajudicial, traz também, exemplos em que a irracionalidade humana se sobrepõe a toda e qualquer forma de decisão justa (autotutela). Porém, na medida em que o Estado foi se firmando, e afirmando-se, conseguiu adentrar na liberdade dos particulares e, consequentemente, de forma gradativa, "absorver o poder de ditar as soluções dos conflitos" (CINTRA, GRINOVER E DINAM ARCO, 2006, p. 20).

A jurisdição deixou de ser apenas dizer o direito, ou seja, "identificar a norma de direito objetivo preexistente (ou de elaborá-las, se inexistente) e [...] fazê-la atuar numa determinada situação" (BERM UDES, 1995, p. 19, apud CARNEIRO, 2009, p. 4), passando a ser "uma forma de exercício da soberania estatal" (CARNEIRO, 2009, p. 3), juntamente com a administração e legislação.

Outrossim, muitos são os conceitos (clássicos) de jurisdição. Aqui serão, sinteticamente, apresentados três, o de Chiovenda, de Carnelutti e de Galeno Lacerda.

Chiovenda parte do pressuposto de que o Estado é o responsável pelo monopólio da produção das leis, logo apenas ele pode aplicar a lei ao caso concreto. Assim, jurisdição é "a função do Estado que tem por escopo a atuação da vontade concreta da lei por meio da substituição, pela atividade de órgãos públicos, da atividade de particulares ou de outros órgãos públicos, já no afirmar a existência da vontade da lei, já no torná-la, praticamente, efetiva" (CHIOVENDA, 1943, p. 137).

Carnelutti, por seu turno, na leitura de Silva (p. 67), destaca que a jurisdição "consiste na justa composição da lide, mediante sentença de natureza declarativa, por meio da qual o Juiz dicitius; daí porque, segundo ele, não haveria jurisdição no processo executivo". E continua 0 autor:

Revista de Direito Púbuco, LondRINA, V. 6, N. 2, P. 103-119, AGO/SET. 2011. 
Sem haver lide, não há atividade jurisdicional. A jurisdição é criada e organizada pelo Estado precisamente com a finalidade de pacificar, segundo a lei, os conflitos de interesses das mais diferentes espécies, abrangendo não só os conflitos de natureza privada, mas igualmente as relações conflituosas no campo do direito publico. (SILVA, p. 67)

Galeno Lacerda, por sua vez, atribui ao conceito carneluttiano de lide uma maior amplitude. Entende ele que Carnelutti teria esquecido

[...] que há interesses relevantes pertencentes a outras esferas da ordem jurídica e que, assim, a lide nem sempre se manifesta em conflitos, apenas entre particulares. Considerando os valores antinômicos tutelados pelo direito, podem perfeitamente ocorrer, num processo, conflitos, quiçá mais relevantes, entre interesses públicos ou de ordem publica, com inexistência de conflito privado, sem que a atividade do juiz deixe de ser jurisdicional [...] Modificando o conceito de Carnelutti impõe-se afirmar, portanto, que existe lide sempre que houver, também, conflito de interesse públicos ou particulares, a serem compostos pelo processo (LACERDA, 2006, p. 67-68).

Observa-se, da citação, que o dizer o direito é reservado ao Estado. Não há espaços para outras formas de resolução de conflitos, inclusive daqueles de natureza privada.

Além dessas, é possível atribuir à jurisdição um conceito contemporâneo. Destacase o conceito de Marinoni (2006, p. 136-138), para quem a jurisdição tem "o dever de prestar ao cidadão a tutela que decorre da sua posição jurídica", aplicando a lei "na dimensão dos direitos fundamentais, fazendo sempre o resgate dos valores substanciais neles contidos", e que contém "um nítido plus em relação à teoria chiovendiana".

Em síntese, pode-se dizer que jurisdição é a atividade estatal "pela qual o Estado cumpre o dever de, mediante um devido processolegal, administrar a justiça aos que a solicitaram" (CARNEIRO, 2009, p. 3).

Pela jurisdição, como se vê, os juízes agem em substituição as partes, que não podem fazer justiça com as próprias mãos (vedada a autodefesa; a elas, que não mais podem agir, resta a possibilidade de fazer agir, provocando o exercício da função jurisdicional. E como a jurisdição se exerce através do processo, pode-se provisoriamente conceituar este como instrumento por meio do qual os órgãos jurisdicionais atuam para pacificar as pessoas conflitantes, eliminando os conflitos e fazendo cumprir o preceito jurídico pertinente a cada caso que lhes é apresentado em busca de solução. (CINTRA, GRINOVER E DINAM ARCO, 2006, p. 23) 
A questão principal a ser destacada enfrenta as concepções clássicas de jurisdição, que tendem a tornar todo o conflito judicializado, ou seja, levá-lo ao Poder Judiciário para solucionar. Com Cintra et al (2006), com Marinoni (2006) e, em particular com Wambier (2010) abre-se um campo novo para pensar o direito processual, não mais nos parâmetros do século XIX, mas a luz dos princípios inscritos na Constituição de 1988.

Conforme salientou Scaciota (2008, p. 10), em sua dissertação de mestrado apresentada à Faculdade Autônoma de Direito - FADISP, o Estado tem que ser visto como

[...] um parceiro do cidadão na busca da solução dos conflitos visando à pacificação social. Dar a cada um o que é seu. Evidentemente que a cultura enraizada em nós, de litigar a qualquer custo, recorrer até as últimas instâncias, não se conformar com as decisões, quando no mais das vezes sem obediência ao bom-senso, razoabilidade, ética, boa-fé, contribui, sem dúvida para a morosidade da Justiça.

É necessário avançar, construir uma nova cultura de convivência e paz social que supere a cultura da judicialização dos conflitos. Ora, como destaca Rouland (2003, ps. 7 e 8):

Assim como a saúde não se define pela doença, o direito não se reduz ao contencioso. Vivemos a maioria das relações pessoais e sociais às quais o direito dá uma estrutura sem necessitar recorrer aos tribunais. A maioria dos desacordos conjugais ou das brigas de vizinhança se extingue bem antes que 0 juiz seja solicitado a solucioná-los; a maior parte dos contratos é normalmente executada pelas partes. Isso quer dizer que o direito mais fornece modelos de conduta do que pune comportamentos. $E$, se contencioso há, ele não é majoritariamente penal. Interrogue as pessoas de seus círculos que recorrem a justiça: há poucas possibilidades que tenham comparecido perante o tribunal de júri, ou mesmo em tribunal criminal. A maioria dos processos é civil ou comercial, o que tranqüilizaria o grande publico, se ele o soubesse. E, se devemos apesar de tudo penetrar nele, não é forçosamente para perder toda iniciativa diante de um inexorável castigo. No processo anglo-saxão, $90 \%$ dos processos penais são acertados de modo negociado. É o pleabargaining; as partes chegam a uma solução amigável, submetem-na ao juiz, que o mais das vezes se contenta em registrá-la. Quanto à pena, a indulgência pode suprimi-la: graça presidencial, perdão da lei (anistia) ou do juiz (reabilitação e indulto, que apagam a condenação).

Enfim, o direito pode falar de maneira diferente que não por ordens e ameaça para poder aplicar-se. Para mesmo fazê-lo com cada vez maior freqüência: é possível perguntar-se se seu futuro não está na atenuação de sua função repressiva em proveito de um papel incitativo. (grifo nosso)

Nessa senda, Delgado (2001, p. 5) apresenta que

Forma-se, também, uma consciência doutrinária de que não se deve entregar ao Estado, de modo absoluto, a, responsabilidade para resolver as desavenças

Revista de Direito Púbuco, LondRINA, V. 6, N. 2, P. 103-119, AGO/SET. 2011. 
decorrentes dos relacionamentos humanos e das pessoas jurídicas. Há de a sociedade, por via dos seus estamentos mais categorizados e organizados (sindicatos, associações, clubes de vizinhança, igrejas, universidades, etc), contribuir para que se estabilizem os distúrbios decorrentes de querelas individuais ou coletivas, impondo, com força coercitiva e definitiva, decisão representativa do direito aplicado ao caso. (grifo nosso)

Assim questiona-se: judicialização de todos os conflitos, pra quê?

\section{Jurisdição e arbitragem}

Não há maiores questionamentos, atualmente, quanto a possibilidade de estabelecer outros métodos de solução de conflito e, em especial a arbitragem.

A uma, como já dito, pois não se pode negar que

A arbitragem, como meio processual para a solução dos conflitos, sem a presença do Poder Judiciário, visa a consolidar os anseios daqueles que estão insatisfeitos com a demora na entrega da prestação jurisdicional, não só porque contribui para aumentar 0 grau de discórdia com o seu semelhante, mas, também, pelo fato de Ihe ser negado o direito constitucional de ver o seu direito reconhecido em tempo razoável de ser possível o seu gozo e a sua fruição (DELGADO, 2001, p. 16).

A duas, porque a arbitragem atende os pressupostos da jurisdição ("conflito de interesses, qualificado pela pretensão de alguém e a resistência de outrem" - SILVA, 1997, p. 67), bem como se justifica no "vício" da teoria de Carnelutti descrita por Silva (1997, p. 68), "que procura definir o ato jurisdicional indicando não o que ele é, mas aquilo a que ele serve; não o seu ser, mas a sua função, ou a sua finalidade", ou seja, a justa composição da lide isso porque, como bem apresenta Galeno Lacerda, a jurisdição só existe por causa do conflito e para solucioná-lo (SILVA, 1997, p. 68).

A três, pois como ser restará demonstrado, o procedimento da arbitragem carrega, em sua gênese, as mesmas garantias mínimas expostas por Comoglio ${ }^{4}$ que asseguram um processo constitucional.

\footnotetext{
${ }^{4}$ Por questões didáticas se retoma os pressupostos: “a) A relação de instrumentalidade necessária entre o direito material e o processo, como premissa indispensável de sua atuação; b) 0 acesso às cortes de justiça e os fatores de desigualdade socioeconômica, que o limitam irrazoavelmente; c) a independência, a autonomia e a imparcialidade do juiz; d) exercício em condições adequadas e paritária, dos direitos de ação e defesa em juízo; e) o direito das partes a um processo justo e equo; f) a adequação e a efetividade dos instrumentos de tutela jurisdicional (de forma qualificada, diante de órgãos de justiça constitucional, e de forma ordinária, diante de órgãos de justiça comuns) das garantias processuais fundamentais".
} 
Há os que ousam afirmar que a arbitragem se consagra "como sendo instrumento da abertura de uma nova fase do Direito Processual Brasileiro, haja vista ela apresentar-se como entidade possuidora de objetivos harmônicos com os desejos da cidadania" (DELGADO, 2001, p. 12). E mais, antecipa-se a anunciar a arbitragem como direito processual de quarta geração ${ }^{5}$ ao se contrapor "aos sistemas até então adotados para solução de conflitos, onde a presença do Poder Judiciário era considerada indispensável" (DELGADO, 2001, p. 12).

Abrem-se parênteses aqui, para apresentar as gerações do direito processual apresentadas por Delgado (2001, p. 12-3), no sentido de elucidar o assunto.

0 Direito Processual de primeira geração caracteriza-se pelo profundo apego ao formalismo, com regras inspiradas em aumentar o grau da segurança jurídica, porém, possibilitadoras de manobras processuais que favoreciam, especialmente, ao litigante de maior poder aquisitivo e que tinha interesse em fazer demorar 0 resultado da demanda.

o Direito Processual de segunda geração é representado pelo sistema que tentou, embora não tenha conseguido, romper com a burocracia processual. 0 seu mérito consiste em ter abolido determinadas formalidades processuais inúteis e ter consagrada a figura do Juiz ativo, isto é, comprometido com o apanhado das provas e com a justiça da decisão.

0 Direito Processual de terceira geração é o que enfatiza a necessidade de se prestigiarem as ações coletivas, especialmente na proteção dos direitos difusos, estes voltados à proteção do meio ambiente, paisagístico, do consumidor, etc. Por fim, vive-se, na época contemporânea, o Direito Processual de quarta geração, onde a arbitragem se situa. É a utilização de um instrumento voltado para a solução dos litígios sem a presença obrigatória do Poder Judiciário. É a própria sociedade, de modo organizado, aplicando o direito, utilizando-se das associações que a compõem. É uma nova era do Direito Processual que necessita evoluir até alcançar os denominados Tribunais de Vizinhança. É a busca de intensificação de outros meios de acesso do cidadão ao encontro da Justiça, por essa reivindicação se constituir em um direito constitucional de natureza subjetiva.

Entretanto, as reticências ao reconhecimento da arbitragem como instrumento de realização da justiça, ainda permanecem, muito embora essa etapa já devesse ter sido ultrapassada. Muito se discute ainda, sobre se a arbitragem seria jurisdição propriamente dita, equivalente jurisdicional ou ainda meramente contratual. A doutrina se divide equilibradamente.

Ressalta Gajardoni (2002, p. 190) que,

\footnotetext{
${ }^{5}$ Sobre a matéria, indica-se a leitura de DELGADO, J. A. A arbitragem: direito processual da cidadania. Disponível em: http://www.buscalegis.ufsc.br/revistas/index.php/buscalegis/article/viewFile/29760/29314
}

Revista de Direito Púbuco, Londrina, V. 6, N. 2, P. 103-119, AGO/SET. 2011. 
A discussão, embora possa parecer meramente acadêmica, é de suma importância, pois da conclusão tomada decorrerá uma série de efeitos práticos, notadamente no pertinente à intervenção da jurisdição estatal nos aspectos em que a Lei de Arbitragem ou a convenção de arbitragem for omissa (pontos de contato com a jurisdição estatal).

Para os que entendem ser a arbitragem meramente contratual (por todos: Joel Dias de Figueiredo ${ }^{6}$ e Eduardo Arruda Alvim ${ }^{7}$ ) fundamentam seus argumentos na possibilidade do Estado permitir que alguns casos, que devem estar previstos em lei, sejam resolvidos por juízes privados, num regime substitutivo da jurisdição uma vez que buscam o mesmo fim: pacificação social.

Para os que negam peremptoriamente o caráter jurisdicional à arbitragem (i.e.: Alexandre Freitas Camara ${ }^{8}$, Candido Dinamarco ${ }^{9}$, Teori Zavascki e LuisM arinoni ${ }^{10}$ ) justificam que a jurisdição é monopólio do Estado, sendo a arbitragem um meio alternativo de solução de conflitos, também desenvolvido por um processo, porém realizado "fora do âmbito do exercício do poder estatal pelo juiz" (DINAMARCO in Carneiro, p. 56) e por pessoa não investida na autoridade de juiz, sendo indispensável que este tenha prestado concurso público, nos termos do artigo 93, I da CF - sendo esse poder indelegável. Como destaca Marinoni (2006, p. 147 e ss.) "não haveria possibilidade de delegação de poderes atribuídos pela própria Constituição para um árbitro privado". E mais, salienta Teori Zavascki que “Nem se poderia, mediante lei ordinária, igualar ato privado com ato de jurisdição, já que isso importaria rompimento do monopólio da função jurisdicional, que pertence ao Estado, por força da Constituição (art. 5, XXXV)" (CARNEIRO, 2009, p. 56).

Por outro lado a doutrina contrária rebate as afirmações acima incisivamente, inclusive com fundamento constitucional, no seguinte modo.

\footnotetext{
${ }^{6}$ Sobre o assunto indica-se: FIGUEIREDO, J. D. Manual da Arbitragem. São Paulo: Editora Revista dos Tribunais, 1997.

${ }^{7}$ Sobre o assunto indica-se: ALVIM, E. A. Curso de Direito Processual Civil. São Paulo: Editora Revista dos Tribunais, 1999. Vol. I.

${ }^{8}$ Sobre 0 assunto indica-se: CAM ARA, A. F. Arbitragem. São Paulo: Editora Lumen Juris, 1997.

${ }^{9}$ Sobre 0 assunto indica-se: DINAM ARCO, C. Instituições de direito processual civil. São Paulo: Malheiros Editora, 2001, vol. III.

10 Sobre 0 assunto indica-se: MARINONI, L. G. Teoria Geral do Processo. São Paulo: Editora Revista dos Tribunais, 2006.
} 
Quanto à afirmação de que a jurisdição é monopólio do Estado, pode-se afirmar que 0 Estado detém a atividade com eficácia vinculativa. Seu objetivo: eliminar a lide, "declarando ou realizando o direito em concreto" (CARNEIRO, 2009, p. 6).

Todavia, deve-se ter a cautela de não confundir tutela jurisdicional com tutela judicial. Ressalta Gajardoni (2002, p. 190) que

Em absoluto, sem pretensão de nos desviar do objeto do presente estudo, trilhando longo caminho na defesa da tese da jurisdicionalização da arbitragem, entendemos conveniente, apenas, ressaltar que a não caracterização do instituto como exercício de tutela jurisdicional - nos novos moldes, sem necessidade de homologação do laudo pelo Poder Judiciário - esbarraria no dispositivo constitucional que veda o afastamento da tutela jurisdicional em casos de lesão ou ameaça de direito (art. $5^{\circ}, \mathrm{XXXV}$ ).

Foi propositadamente dito "tutela jurisdicional", pois o dispositivo constitucional comentado, embora aponte "a lei não excluirá da apreciação do Poder Judiciário lesão ou ameça de direito", teve por escopo dar a todo e qualquer homem tutela jurisdicional, e não tutela judicial.

Diante disso deve-se ter em mente, como bem enfatizou Diddier Junior (2008, p.

61), que :

[...] não é correto dizer que há monopólio de seu exercício. 0 estado brasileiro autoriza, não só pela Lei, mas também em nível constitucional (Art. 114, §§1ํㅡ e 2으, CF), o exercício da jurisdição por juízes privados. Perceba-se, ainda, que ao escolher a arbitragem, os indivíduos não estão abrindo mão de suas garantias processuais básicas e indispensáveis (os corolários do devido processo legal), porquanto deva 0 árbitro respeitar todas elas, sob pena de invalidade de sua decisão. (grifo nosso)

Ora, é certo que a arbitragem é constituída através de convenção entre as partes, pelo compromisso arbitral, porém o mesmo não exclui a jurisdição, apenas a via judicial. A lide ainda será resolvida, só que perante a justiça arbitral. Não há renúncia. Há escolha. E, em “[...] ambas há, por óbvio, a atividade jurisdicional” (NERY JUNIOR, 1992, p. 77).

Quanto à pessoa do árbitro, surgem dúvidas quanto a sua investidura, uma vez que "seus poderes nascem da convenção, sendo essencialmente temporários, oriundos da vontade das partes, que os podem revogar a qualquer momento (FIUZA, 2005,p. 123).

Sucede que, como já visto, a jurisdição não é uma função exclusiva do Poder Judiciário (quiçá do Estado), pois os outros poderes do Estado (Legislativo e Executivo) podem exercer a função Jurisdicional. E lembra Diddier Jr. (2008, p. 81):

Revista de Direito Púbuco, LondRINA, V. 6, N. 2, P. 103-119, AGO/SET. 2011. 
E não há que se falar em delegação de poderes, pois os árbitros não tomam do estado o exercício da jurisdição pública, mas sim, exercem um tipo especial de jurisdição privada, autorizada pelo Estado. Relembre-se, também, que nem todo magistrado investe-se na função jurisdicional por meio de concurso. Ministros de tribunais superiores são, por exemplo, nomeados pelo Presidente da República. Não há delegação aí. Haveria se o árbitro, uma vez indicado, delegasse a função a outro sujeito ou se o juiz estatal, uma vez provocado, transferisse sem convenção de arbitragem, o julgamento da causa a um juiz privado. (grifo nosso)

Quanto à atividade do árbitro a mesma não pode ser confundida com a do juiz, embora ambos tenham o dever de julgar, uma é função pública e outra privada. A lei $n$. 9.307/96, em nenhum momento utiliza a expressão juiz arbitral, bem como não afirma que o árbitro é um juiz. Apenas proclama, em seu artigo 18, que o árbitro é juiz de fato e de direito, logo o árbitro tem que decidir sobre o fato e sobre o direito. Nota Grinover (apud CARNEIRO, 2009, p. 56) (doutrina contrária) que parece "uma filigrana, mas não é: a lei não diz que o arbitro é 'o' juiz de fato e de direito, mas que é 'juiz de fato e de direito'; juiz no sentido de apreciar e decidir, mas o 'o juiz' que exerce função jurisdicional."

Porém, destaca Carneiro (2009, p. 6-7) que:

A atividade jurisdicional revela-se por decisão dotada de eficácia vinculativa plena, porquanto a sentença de mérito faz 'coisa julgada entre as partes'. [...] A jurisdição dirige-se, essencialmente, a eliminação (ou composição) do conflito de interesses existente (ou virtual) entre as partes.A lide é eliminada mediante a declaração e aplicação do direito incidente ao caso concreto (processo de conhecimento) ou mediante a realização do direito (processo de execução).

Na mesma senda acompanha Diddier Jr. (2008, p. 83):

A decisão arbitral fica imutável pela coisa julgada material. Poderá ser invalidada a decisão, mas ultrapassado o prazo nonagesimal, a coisa julgada torna-se so berana. É por conta desta circunstancia que se pode afirmar que a arbitragem, no Brasil, não é equivalente jurisdicional: é propriamente jurisdição, exercida por particulares, com autorização do Estado e como conseqüência do exercício do direito fundamental de auto-regramento (autonomia privada).

Verifica-se que a sentença no procedimento arbitral também tem por objetivo eliminar o conflito existente entre as partes, buscando (diferentemente do procedimento judicial) "a retomada do relacionamento" (FIUZA, 2005, p. 38) entre as partes. 
E essa satisfação proporcionada às partes envolvidas é vista por Martins (2008) na introdução de sua obra, como vantagem na utilização deste instituto. Diz ele:

É lei cidadã, que permeia o inconsciente social, o consenso e a solidariedade. Instiga a ética e a moral. Agiliza e possibilita o exercício de direito natural do cidadão, isto é, 0 acesso à justiça. Confirma e reforça o sentido de cidadania pela cooperação do cidadão comum com o Estado, na importante tarefa de pacificação dos conflitos. Atende, enfim, ao devido processo substantivo.

Verifica-se assim que a arbitragem se identifica como meio capaz de entregar a prestação jurisdicional na mesma intensidade que o Estado, buscado a dissolução da lide, muito embora ausente o Poder Judiciário, mas por ele autorizado (art. 114, $\S \S 1$ e e 2ํㅡ, CF), por um árbitro contratualmente constituído com autorização legal (Lei. 9.307/96), através de um procedimento que atende os princípios constitucionais do processo ${ }^{11}$, cuja decisão terá apreciado o fato e o direito e, após o prazo nonagesimal, pode se tornar imutável pela coisa julgada material.

\section{Conclusão}

A história apresenta que durante alguns séculos vigorou, como forma de resolver os conflitos, meios que não investissem no Estado a função de solucioná-los. Porém, com o passar do tempo, o Estado passou a interferir cada vez mais nas liberdades privadas, de modo a avocar para ele a legitimidade e ser o único e exclusivo ente a realizar a jurisdição.

Sucede que cresceu a percepção de que o Estado tem falhado na sua missão pacificadora, e logo se percebeu, também, que o Estado não seria capaz de dirimir toda a massa de controvérsias levada aos tribunais. E esse número aumenta diariamente. Diante disso renasceu o interesse para as modalidades não estatais de solução de conflitos, tratadas como meios alternativos de pacificação social. Isso porque, pacificar, dizendo a cada um o

\footnotetext{
${ }^{11}$ Os princípios que deve ser obrigatoriamente observados no procedimento arbitral sem os quais não haveria um julgamento justo no ver de Fiuza são: Contraditório e ampla defesa, igualdade das partes, imparcialidade do árbitro, disponibilidade, livre investigação, impulso oficial, oralidade, imediação, identidade física do árbitro, concentração, persuasão racional do árbitro ou livre convicção, motivação das decisões, lealdade, boa-fé, honestidade, instrumentalidade das formas, causalidade, interesse, oportunidade, fungibilidade e peremptoriedade no que tange aos recursos (1995, ps. 137-141).
} 
seu direito (realizar o acesso à justiça), é jurisdicionar, e como salientou Carnelutti não importa o meio, ou seja, o seu ser, mas sim a finalidade do ato.

Desta forma, "ganhou corpo a consciência de que, se o que importa é pacificar, se torna irrelevante que a pacificação se faça por obra do Estado ou por outros meios, desde que eficientes e justos" (GRINOVER, 2010, p. 2).

E dentre os diversos meios alternativos de resolução de conflitos, o presente trabalho destacou a arbitragem que, assim como o Estado, produz com sua decisão um ato jurisdicional, muito embora ainda haja na doutrina posições contrárias.

Inobstante cada procedimento possuir suas características peculiares, a sentença no procedimento arbitral, assim como a proferida pelo Poder Judiciário, também tem por objetivo eliminar o conflito existente entre as partes, buscando (diferentemente do procedimento judicial) "a retomada do relacionamento" (FIUZA, 2005, p. 38) entre as partes.

Como conseqüência, é possível afirmar que a arbitragem se identifica como meio capaz de entregar a prestação jurisdicional na mesma intensidade que o Estado, buscado a dissolução da lide, muito embora ausente o Poder Judiciário, mas por ele autorizado (art. 114, $\S \S 10$ e 2ํㅡ, CF), por um árbitro contratualmente constituído com autorização legal (Lei. 9.307/96), através de um procedimento que atende os princípios constitucionais do processo, cuja decisão terá apreciado o fato e o direito e, após o prazo nonagesimal, pode se tornar imutável pela coisa julgada material.

\section{Referências}

BARUFFI, H. M etodologia da Pesquisa: orientações metodológicas para a elaboração da monografia. 4.ed.rev. e atual.Dourados: HBedit, 2004.

CARNEIRO, A. G. Jurisdição e competência: exposição didática. Área do direito processual civil. 16.ed. São Paulo: Editora Saraiva, 2009.

CINTRA, A. C. de A.; GRINOVER, A.P. e DINAM ARCO, C. R.Teoria geral do processo. 22a edição. São Paulo: Malheiros, 2006.

CHIOVENDA, G. Instituições de direito processual civil. São Paulo: Editora Saraiva, 1943. Vol. I. 
COSTA, R. M. P. da. O processo como instrumento de garantia dos direitos fundamentais no Estado Democrático de Direito In Estado democrático de direito e direitos humanos. NETO, A. J. de M . (org). São Paulo: Editora Saraiva, 2010. p. 71 - 93.

DIDIER JUNIOR, F. Curso de direito processual civil: teoria geral do processo e processo de conhecimento. 9.ed. Salvador: Editora JusPodivm, 2008. Vol. I.

DELGADO, J. A. A Arbitragem:direito processual da cidadania. In Revista Jurídica. São Paulo, 2001. Ano 49. N. 282. P. 5-18. Disponível em:

http:// www.buscalegis.ufsc.br/revistas/index.php/buscalegis/article/ viewFile/29760/29314

FIUZA, C. Teoria geral da Arbitragem. Belo Horizonte: Editora DelRey, 2005.

GAJARDONI, F. da F. Aspectos fundamentais de processo arbitral e pontos de contato com a jurisdição estatal. In Revista de Processo, São Paulo, n. 106, p. 189-216, abr.-jun. 2002.

GRINOVER, A. P. A inafastabilidade do controle jurisdicional e uma nova modalidade de autotutela. Disponível em:

http://ultimainstancia.uol.com.br/ensaios/ler_noticia.php?idNoticia=22108 Acesso em: 25/05/2010.

LACERDA, G. Teoria geral do Processo. São Paulo: Editora Forense, 2006.

M ARTINS, P. A. B. Apontamentos sobre a Lei de Arbitragem. Rio de Janeiro: Editora Forense, 2008.

M ARINONI, L. G. Teoria Geral do Processo. São Paulo: Revista dos Tribunais, 2006.

NERY JUNIOR, N. Princípios de Processo Civil na Constituição Federal. RT: São Paulo, 1992, p. 77.

ROULAND, N. Nos confins do direito: antropologia jurídica da modernidade. Trad. Maria Ermantina de Almeida Prado Galvão. São Paulo: Editora Martins Fontes, 2003.

ROCHA, C. L. A. O mínimo existencial e o princípio da reserva do possível In Revista Latinoamericana de estudos constitucionais. N. 5. Jan/jun. Del Rey: Belo Horizonte, 2005.

SCACIOTA, G. Arbitragem: forma alternativa de solução de conflitos. 2008, 170f. Dissertação (Função Social do Direito). Faculdade Autônoma de Direito - FADISP. São Paulo: 2008.

SILVA, O. B. da. GOM ES, F. L. Teoria Geral do Processo Civil. São Paulo: Revista dos Tribunais, 1997.

WAMBIER, L. R.; WAM BIER, T. A. A. Anotações sobre a efetividade do processo. In: Revista dos Tribunais, São Paulo, SP, v. 92, n. 814, 2003, p. 63-70.

Revista de Direito Púbuco, Londrina, V. 6, N. 2, P. 103-119, AGO/SET. 2011. 
- Notas de aula da Disciplina Teoria Crítica do Processo de Conhecimento. Curso de M estrado em Processo Civil e Cidadania. Umuarama/PR: Universidade Paranaense UNIPAR, 23/03/2010.

Artigo recebido em:

05 de julho de 2011

Artigo aprovado em:

26 de agosto de 2011 